22. [Новокузнецкий] Научно-технический музей имени академика И. П. Бардина // VizitKuzbass : [сайт]. - Кемерово, 2021. - URL: https://visit-kuzbass.ru/guide/chto-posetit/nauchno-texnicheskij-muzej-imenii.p.bardina (дата обращения: 05.09.2021).

23. В Тюмени открылся музей Уватского проекта [OОО «РН-Уватнефтегаз» НК «Роснефть»]// ПАО «Нефтяная компания «Роснефть». - Москва, 2021. - URL: https://www.rosneft.ru/press/subsidiaries/item/185167/ (дата обращения: 20.09.2021).

24. Открытое фондохранение [Музея геологии, нефти и газа г. Ханты-Мансийска]. Выставка «Причудливый мир камня» // БЮ Ханты-Мансийского автономного округа - Югры «Музей геологии, нефти и газа»: [сайт]. - Ханты-Манскийк, 2021. - URL: http://muzgeo.ru/VT/otkrytoe-fondokhronenievystavka-prichudlivyy-mir-kamnya.php (дата обращения: 05.09.2021).

25. Менш, П. ван. Коммуникация: язык экспозиции // Вопросы музеологии. - 2014. - № 1. C. $254-272$.

Darina E. Shorina, Ph. D. in Cultural Studies

Altai State University (Barnaul, Russia) shorinadarina@mail.ru

\title{
PECULIARITIES OF EXHIBITION AREAS DESIGNING OF INSTITUTIONAL MUSEUMS OF WEST SIBERIA (RUSSIA)
}

Abstract. The paper considers basic methodological principles and theoretical approaches to arranging exhibition spaces of the today's institutional museums operating in West Siberia (Russia). Specifics of departmental museums as a sort of museum formations with debatable classification features is cleared. Description of modern conceptions of subject-spatial designing of exhibition areas in a museum is given; the author of the article outlines her own view on a technology of arranging exhibition in an institutional museum, names typical elements of its topic structure, analyses attractive architectural and artistic decisions in designing museum exhibitions.

Key words: classification of museums, institutional museums, museum network, museums of West Siberia, museum item, museum exhbition, design of museum exhbition, museum communication.

УДК 7.01:792(470+571+4)

DOI: $10.32340 / 2414-9101-2021-3-40-45$

Н. В. Губина, кандидат филологических наук Алтайский государственный институт культуры (Барнаул, Россия) ninochka4@mail.ru

Е. П. Тагильцева

Алтайский государственный институт культуры (Барнаул, Россия) tag.elena@icloud.com

\section{КРИЗИС КУЛЬТУРНОЙ ИДЕНТИЧНОСТИ В ТЕАТРЕ В КОНТЕКСТЕ АКТУАЛИЗАЦИИ ЭСТЕТИКИ ПЕРФОРМАТИВНОСТИ}

Аннотация. Актуальность статьи обусловлена укреплением позиций перформативной эстетики в культуре и искусстве двух последних десятилетий. В этой связи рассматривается конфликт двух эстетических парадигм театральной культуры: перформативной и психологореалистической. Прослеживается взаимосвязь проявления кризиса театральной культуры с трансформацией культурной идентичности. Уточняется понятие «культурная идентичность», рассматриваются проявления кризиса культурной идентичности в театре. Обнаруживаются эстетические ценности двух парадигм, раскрываются их противоречия, намечаются перспективы исследований идентификационных процессов в современном театре. 
Ключевые слова: культурная идентичность, перформативная эстетика, психологореалистический театр, эстетические ценности, кризис идентичности в театре, русский театр, европейский театр.

За прошедшие два десятилетия позиция перформативной эстетики в современном искусстве заметно укрепилась. Появляются новые формы выразительности в театре, усложняются и насыщаются зрелищностью спектакли. Однако с трансформацией духовных ценностей в условиях критического периода культуры, можно констатировать угасание идейно-смысловой целостности произведений искусства, рафинированность и потерю аутентичности.

В связи с этим осмысление феномена культурной идентичности в театре является одной из актуальных задач культурологии и требует уточнения терминологии. Дискурс идентичности является центральным для социогуманитарного, в том числе культурологического знания конца XX - начала XXI века. Об этом свидетельствует ряд работ: К. Л. Япринцевой «Феномен культурной идентичности в пространстве культуры», Ю. А. Шубина «Традиция как ресурс социально-культурной идентичности личности в современном обществе», Л. В. Мельниковой «Трансформация российской культурной идентичности» и др. Итогом научной дискуссии стало разведение понятий идентификации и идентичности (соответственно, как процесса и результата), выделение видов (индивидуальной и групповой) и форм идентичности (национальная, этническая, культурная, религиозная, территориальная и т. д.), выделение факторов и механизмов её формирования и др. [1, с. 87].

При попытке рефлексии по поводу сущности понятия «культурная идентичность» можно констатировать отсутствие единого общепринятого определения в силу исследовательских позиций по отношению к нему. Однако в разнообразных трактовках можно выделить общее: 1. Ядром культурной идентичной является образ самого себя, слитый с определенной культурой, в целостном восприятии действительности индивидом [2, с. 762]; 2. Формирование культурной идентичности связано с менталитетом, ценностными установками определенной культуры, которые закрепляются через традицию [2, с. 762]; 3. Определение культурной идентичности осуществляется на основе противопоставления «своей» и «чужой» ценностных систем [3, с. 174]; 4. Обретение культурной идентичности осуществляется через институты-механизмы: политика, право, мораль, религию, искусство и др. [4, с. 23].

Кризис идентичности как одного из сложнейших качеств человека, в котором проявляется его связь с культурой, обусловливается в первую очередь утратой смыслообразующих ценностей, утратой социальных ролей, утратой образа «я» [5, с. 122]. Идентичность есть продукт коммуникации, в том числе художественной. Художественное пространство, являясь сферой идентификации, отражает кризис через двоякий процесс: с одной стороны, активное сохранение традиции как фактора культурной идентичности, и с другой стороны, разрушение традиционных форм, поиски новой культурной идентичности, иных её оснований.

В театре рубежа XX-XXI века идентификационная полярность проявилась как конфликт двух эстетик: традиционно-реалистического и перформативного театра.

Кризис культурной идентичности породил две крайние позиции: традиционалистскую и постмодернистскую. Сторонники традиционалистской культурной идентичности убеждены, что в театре происходит кризис гуманистических ценностей, выраженный через обилие провокаций, эпатажа, нецензурной лексики, деконструкцию классической драматургии и прозы, что приводит к разрушению идентичности личности актёра, режиссёра, зрителя. Апологеты постмодернизма, напротив, убеждены, что в театре протекает закономерный процесс, который ведет к разрушению классического гуманизма, традиционных ценностей и к утверждению нового гуманизма и новой постмодернистской идентичности.

Русский театр, с драматургией А. П. Чехова, А. Н. Островского, М. Горького, и режиссурой К. С. Станиславского, В. И. Немировича-Данченко, Е. Б. Вахтангова, воспринимается как составляющая традиционной культурной идентичности. Соответственно, столкновение двух эстетик, 
обусловленное кризисом идентичности, породило ряд конфликтов в театре, вызвавших общественный резонанс.

Примером может служить спектакль «Первый хлеб» на сцене театра «Современник», где в главной роли сыграла народная артистка РФ Лия Ахеджакова. Постановка взбудоражила общественность и стала поводом для официального обращения в Генпрокуратуру от общественной организации «Офицеры России», в котором содержится претензия о пропаганде в спектакле однополой любви и оскорблении ветеранов [6].

Многие эпатажные спектакли Константина Богомолова стали причиной разобщения зрительской аудитории и непримиримого столкновения полярных мнений. Это связано с определенными провокационными фактами, например, приглашением трансгендера Натальи Максимовой в постановку «Вишневого сада» на роль Раневской. Спектакли «Идеальный муж. Комедия» в Московском художественном театре им. А. П. Чехова, «Норма» в Театре на Малой Бронной, «Ай Фак. Трагедия» в Мастерской Брусникина и др. также были приняты неоднозначно и вызвали определенное сопротивление.

Подобные конфликты являются нередкими событиями в культурно-информационном пространстве, и по-разному оцениваются театральной общественностью. Полагаем, столкновение разных эстетик обусловлено одновременным сосуществованием парадигмы драматизма и постдраматизма, усилением влияния перформативной эстетики, художественные приёмы которой интерпретируются как «соединение несоединимого»: коммуникативность и отчуждение, провокация и искренность, телесность и ментальность и т. д., и определяют существование перформанса «на границе между искусством и действительностью» [7, с. 191]. Очевидна логика биполярности перформанса, соединившего признаки искусства и действительности, а потому для многих сложно определяемого: как собственно «искусство» / «сверхискусство» (больше, чем искусство) / «неискусство» (недоискусство).

Осмысление процессов, происходящих в европейском театре, принадлежат известному немецкому театроведу Э. Фишер-Лихте. В книге «Эстетика перформативности» Э. Фишер-Лихте концентрирует внимание непосредственно на свойствах перформативности, основополагающим признаком которой считает событие, возникающее между актером и зрителем. Событие в эстетике перформативности организуется с помощью провокативных средств, результат воздействия которых не всегда предсказуем и носит в целом импровизационный характер. «Перформер - не актер, он не играет роль персонажа, а демонстрирует свое «присутствие» и даже «умерщвление» своего тела» [8, с. 105]. Телесность в перформативной эстетике трактуется существованием трёх основных видов тел: тело-жертва (использование приёмов нанесения телесных повреждений, членовредительство и демонстрация физической боли и психологического дискомфорта), трансгрессирующее тело (получение опыта расширения возможностей человеческого тела и демонстрации обновленного тела; либо выражено обращенностью к скрытым внутренним резервам природного тела, либо в преодолении границ тела с помощью научных технологий) и алеаторное тело (тело, лишенное какой-либо организации, упорядоченности, это тело-поток) [9, с. 171].

В отличие от драматического представления перформанс проявляется новой формой коммуникации, в результате которой зритель становится со-участником представления. Наиболее очевидными средствами достижения эффекта обратной связи между перформером и публикой являются провокация и эпатаж. Кроме того, в перформативном искусстве анализ художественного произведения смещается с формы и содержания арт-объекта на социальный контекст: место, время, широта медиараспространения, успех/неуспех воздействия того или иного художественного акта на адресата $[10$, с. 26]. Важнейшими эстетическими ценностями перформативного искусства являются обусловленная телесность, событийность как акт художественной коммуникации, провокация и эпатаж как средство коммуникации со зрителем, попадание в социальный контекст времени.

Большая часть эстетических ценностей в отечественной театральной традиции обусловлена идейными и мировоззренческими категориями. Так, все элементы в системе Станиславского взаимообусловлены и направлены на постижение и раскрытие главной идеи режиссера - 
сверхзадачи спектакля. В связи с этим внимание, воображение, чувство правды и вера, магическое «если бы», логика и последовательность, действие, общение, характерность, предлагаемые обстоятельств и др. рассматриваются в единстве. Кроме того, важным элементом системы является этическая составляющая. Станиславский соединил эстетику и этику, которые являются взаимообусловленными и неразделимыми. Кроме того, одна из главных задач виделась в дальнейшем развитии и углублении этических принципов в искусстве.

Приведем некоторые эстетические ценности, относящиеся к театру психологореалистического направления: действие как основа сценического искусства, правда переживаний, игра «здесь и сейчас», учение о сверхзадаче, организация события, категория «публичное одиночество», высокая артистическая техника и самосовершенствование актёра, воспитание театром. Даже при беглом взгляде, возникает понимание, что в эстетике перформативности и в театре психолого-реалистического направления ценности кардинально отличаются. Единственное, в чем пересекаются две парадигмы, это в трансляции понятия «событие», но при этом, оно имеет совершенно разные трактовки: в перформативной эстетике - это способ коммуникации со зрителем, в психолого-реалистическом театре - это действенный, конфликтный факт, происходящий на сцене, но не за её пределами.

Обращенность к человеческому телу также имеют разный смысловой посыл: в перформативной эстетике - это или разрушение его, или преобразование, или выброс тела в поток (чувств, эмоций), то в классической театральной традиции - это требование точной меры мускульной энергии для каждого движения и для каждого положения тела в пространстве. Категория «публичное одиночество» предполагает органичное существование на сцене и безразличие к зрительской аудитории, в то время как основная цель любого перформанса выйти в контакт со зрителем и даже побудить его к каким-либо действиям.

Но главное, в психолого-реалистическом театре режиссер и актеры стремятся через спектакли оказать очистительное влияние на зрителя, обогатить его новыми мыслями, ощущениями благодаря духовному общению через драматургию, режиссерское решение, актёрскую игру, возвысить дух и привести к катарсису. По-иному понимается цель перформанса - создать живую ситуацию, которая, вписывается в социальный контекст времени и вызывает сильный зрительский резонанс, имеющий плюралистический характер и оставляющий право интерпретации зрителю.

Таким образом, до конца XX века режиссеры, актёры и зрители отечественного театра идентифицировали себя с системой гуманистических ценностей, что выражалось через синтез эстетической и этической составляющих, правду переживаний, учение о сверхзадаче, организацию события, высокую артистическую технику и самосовершенствование актёров. Влияние перформативной эстетики определило увлечение театральных деятелей новой системой ценностей, и соответственно, телесностью, событийностью как актом художественной коммуникации, провокацией и эпатажем как средствами коммуникации со зрителем, попаданием в социальный контекст времени.

Возвращаясь к первоначально заявленной проблеме в статье, отметим, что сегодня в России, как и во всем мире, проявляется кризис как индивидуальных, так и коллективных идентичностей. На данном этапе можно наблюдать появление индивидов, а также групп людей, для которых характерна «размытая идентичность» или полиидентичность, чьё сознание имеет фрагментарный характер, и они уже не способны ответить на вопрос: «кем они являются?» [11, с. 67]. Поскольку одним из наиболее важных условий становления идентичности является усвоение норм и ценностей «своей» социокультурной общности, что возможно только лишь на основе их противопоставления другой «чужой» ценностной системе, постольку появление перформанса закономерно.

Так, исследователь современного искусства М. Каткова в работе ещё 2000 года констатирует: «Следует отметить, что столь нетрадиционные проявления творчества нанесли сокрушительный удар системе ценностей, отринув качественные критерии прошлого и учредив новую эстетику, базовые положения которой были столь эфемерны, что часто вызывали сомнения 
в своём наличии» [12, с. 3]. По мнению М. Катковой, парадигма перформанса размыта по причине эклектических противоречий, составляющих его основу.

Однако, как уже было сказано, за прошедшие два десятилетия перформативной эстетике удалось во многом преодолеть эти противоречия и укрепить свое положение в культурном пространстве. Ее приверженцы совершенствуют эстетические приемы, средства выразительности, возвращая театральной зрелищности главенствующий статус по сравнению с содержанием и идейной наполненностью драматического текста. Форма в перформансе зачастую подменяет его содержание и сама становится содержанием театрального действа, обретая собственные ценности и смыслы, которые извлекаются из перформативного жеста равно как автором, так и актером, и зрителем. Искусство всё больше перестаёт быть образным, в нем последовательно используются технологические методы (коллаж, деконструкция, провокация, эпатаж, цитатность), с помощью которых не рождается, не создаётся, а формально конструируется определённая смысловая реальность. Главным становится не эстетическое восприятие как таковое, а интерпретация произведения; адресованность не к эмоционально-образному, чувственному переживанию, а к интеллектуально-операциональной деятельности человека. Кроме того, отрицание и разрушение смыслов как приём ведёт к тому, что абсолютные духовные ценности сменяются признанием их относительности, необязательности, при этом форма признается абсолютной эстетической ценностью: чем смелее и эпатажнее перформативный жест, тем более его ценность.

С одной стороны, прогрессивно мыслящие режиссёры сами конструируют свою идентичность, транслируя своё видение через спектакли, самостоятельно выбирая среди явлений мировой культуры те художественные принципы и ценности, с которыми себя соотносят. С другой стороны, всё более очевиден зрительский резонанс, так как осуществить собственный выбор всё сложнее: это Чехов или вариации К. Гингаса на тему Чехова, Достоевский или Богомолов $a$ la Достоевский?

В условиях девальвации ценностей попытка определить собственную идентичность может стать механизмом, запускающим формирование новых ценностей. Иными словами, ценностные ориентиры и идентичность являются взаимообусловливающими факторами, поэтому аксиологический подход при изучении идентичности можно рассматривать как один из самых продуктивных и использовать его при дальнейшем изучении заявленной темы.

В эпоху деконструкции, мультикультурализма и кризиса идентичности театр становится поводом для переосмысления своего развития, местом для «философии периферийности, более предпочитающей исключения, нежели правила». Трансформация культурной идентичности порождает кризис театральной культуры, актуализируются новые художественные формы, основанные на новых ценностных принципах. Жанр как конструирующая и организующая структура в театре претерпевает деформацию. Эти процессы приводят театральную культуру к новым формам театральной зрелищности и к новым формам существования самого театра.

Подводя итог, констатируем: кризис культурной идентичности выразился в художественном пространстве театра через конфликт традиционно-реалистической и перформативной эстетики. Поскольку явление перформанса связано с критикой традиционных ценностей и отражает поиски новой идентичности личности в художественном пространстве, эстетика перформативности всё более чётко заявляет о собственных ценностях и возрастающей роли в современном искусстве. В связи с этим возникает необходимость исследования не только проявлений культурной идентичности в театре, но и собственно феномена идентичности современной театральной культуры, для которой актуализация перформативной эстетики является уже не следствием, а одним из важнейших определяющих факторов.

\section{Сиисок литературы}

1. Гаврилина, Л. М. Парадоксы идентичности в художественном пространстве XX - начала XXI века // Вестник Московского государственного университета культуры. - 2021. - № 1. - С. 86-96. 
2. Ольховикова, С. В. Культурная идентичность как проблемное поле современного мифа // Культура, личность, общество в современном мире: методология, опыт эмпирического исследования : матер. XVI междунар. конф. памяти проф. Л. Н. Когана (к 90-летию со дня рождения) (Екатеринбург, 21-22 марта 2013 г.). - Екатеринбург : УрФУ, 2013. - С. 761-766.

3. Шульгина, Д. Н. Кризис культуры и идентичности человека в условиях глобализации // Вестник воронежского государственного университета. Серия: философия. - 2010. - № 2. - С. 173-180.

4. Япринцева, К. Л. Феномен культурной идентичности в пространстве культуры : автореф. дисс. ... канд. культурологии: 24.00.01. - Челябинск, 2006. - 26 с.

5. Волова, Л. А О сущности культурной идентификации и причинах её кризиса в России // Вестник Пятигорского государственного лингвистического университета. - 2005. - № 3. - С. 121-125.

6. Вызвавший общественный резонанс спектакль «Первый хлеб» пройдет в «Современнике»: постановка получила скандальную известность из-за нецензурного монолога героини Лии Ахеджаковой на могиле ветерана // TACC, инф. агентство : [сайт]. - Москва, 2021. - URL: https://tass.ru/kultura/12564023 (дата обращения: 03.10.2021).

7. Кривцова, Ю. В. Концепт перформанса: действие, действенность и действительность современного искусства // Ярославский педагогический вестник. - 2009. - № 4. - С. 188-191.

8. Алесенкова, В. Н. Перформативность в контексте театра // Культурная жизнь Юга России. 2016. - № 2. - C. 103-108.

9. Торопова, А. А. Конструирование перформативной телесности в современном искусстве// Исторические, философские, политические и юридические науки, культурология и искусствоведение. Вопросы теории и практики. - 2017. - № 10-1. - С. 170-172.

10. Осьминкин, Р. С. Коллективные формы художественного перформанса в России начала XXI века : дисс. ... канд. искусствов: 24.00.01. - Санкт-Петербург, 2020. - 316 с.

11. Герасимова, И. А. Проблема сохранения культурной идентичности в условиях глобализации / И. А. Герасимова, В. Ю. Ивахнов // Сервис PLUS. - 2017. - Т. 11, № 2. - С. 66-76.

12. Каткова, М. В. Искусство действия: перформанс - художественное явление второй половины ХХ века : автореф. дисс. ... канд. искусствоведения: 17.00.04. - Москва, 2000. - 27 с.

Nina $V$. Gubina, Ph. D. in Phylology Altai State Institute of Culture (Barnaul, Russia) ninochka4@mail.ru

Elena $P$. Tagiltseva

Altai State Institute of Culture (Barnaul, Russia) tag.elena@icloud.com

\title{
CRISIS OF CULTURAL IDENTITY IN THEATRE IN THE CONTEXT OF MAINSTREAMING OF PERFORMATIVITY AESTHETIC
}

\begin{abstract}
Immediacy of the paper is related with strengthening of points of performative aesthetic in culture and art of last two decades. Accordingly to that, authors consider a conflict between two aesthetic paradigms of theatric culture: performative, on the one side, and psychological and realistic, on the other side. The researchers trace a correlation between appearance of a crisis in theatrical culture and transformation of cultural identity. Also, the paper clarifies a concept "cultural identity", considers manifestations of crisis of cultural identity in theatre, reveals aesthetic values of two paradigms mentioned above, highlights related contradictions, mark perspectives in researching identification process in modern theatre.
\end{abstract}

Keywords: cultural identity, aesthetics of performance, psychological theatre, aesthetic values, crisis of identity in theatre, Russian theatre, European theatre. 